\title{
O Brasil café com leite. Debates intelectuais sobre mestiçagem e preconceito de cor na primeira república*
}

\section{Carolina Vianna Dantas**}

Este artigo analisa algumas formulações de intelectuais sobre mestiçagem e preconceito racial cunhadas durante a primeira república. A abordagem focaliza a diversidade das propostas intelectuais no período - que não se restringiram às teorias raciais e à rejeição de tudo que estivesse associado aos negros e mestiços. As principais fontes são artigos publicados em periódicos da cidade do Rio de Janeiro.

Palavras-chave: Intelectuais - Relações Raciais - Identidade Nacional

Brasil café com leite. Intellectual debates on racial and color prejudice in the First Republic

This article analyzes some intellectuals' formulations, coined during the First Republic, regarding miscegenation and racial prejudice. The approach focuses on the diversity of intellectual propositions within this period, which weren't restricted to racial theories or to the rejection of everything associated with blacks and mestiços. The main sources are articles published in the city of Rio de Janeiro.

Keywords: Intellectuals - Race Relations -National Identity

\footnotetext{
*Artigo recebido em setembro de 2008 e aprovado para publicação em outubro de 2008 . Este artigo é uma versão de um dos capítulos da minha tese de doutorado $O$ Brasil café com leite: história, folclore, mestiçagem e identidade nacional em periódicos. Rio de Janeiro, 1903-1914, defendida em 2007, no Programa de Pós-Graduação em História da UFF. A pesquisa contou com o apoio do GNPq.
}

${ }^{* *}$ Professora da rede municipal de ensino do Rio de Janeiro. 
Le Brasil café com leite. Débats intellectuels surle métissage et les préjugés ethniques de couleur dans la Première République

Cet article fait l'analyse sur des formulations intellectuelles sur le métissage et les préjugés raciaux élaborées au cours de la Première République. L'approche axée sur la diversité intellectuelle de propositions faites dans cette période - qui ne se sont pás limitées à des théories raciales et au rejet de tout ce qui a été associé à des Noirs et à des métis. Les principales sources sont des articles de presse publiés à Rio de Janeiro.

Mots-clés: Intellectuels - Relations Raciales - L'identité Nationale

(...) Na Saúde a dança é uma fusão de danças, é o samba, uma mistura do jongo e dos batuques africanos, do canaverde dos portugueses e da poracé dos índios. As três raças fundem-se no samba, como num cadinho. (...) No samba desaparece o conflito das raças. Nele se absorvem os ódios da cor. O samba é, - se me permitis a expressão - uma espécie de bule, onde entram, separados, o café escuro e o leite claro, e de onde jorra, homogêneo e harmônico, o híbrido café com leite. (Fantasio, pseud. de Olavo Bilac, Revista Kosmos, maio, 1906)

Os variados registros recolhidos em periódicos como a Revista Kosmos (Rio de Janeiro, 1904-1909) e o Almanaque Brasileiro Garnier (Rio de Janeiro, 1903-1914) sobre mestiçagem e preconceito de cor fazem pensar no peso que a defesa da idéia do Brasil como um país aberto à assimilação tinha naquele momento. Analisados em conjunto e comparativamente, esses registros evidenciam o quanto a preocupação com a unidade nacional motivou intelectuais a um mergulho nas "coisas brasileiras" - o que fica evidente, por exemplo, no trecho citado acima. Conseqüentemente, essa produção intelectual enveredouse por uma avaliação do papel dos descendentes de africanos e da mestiçagem para os destinos da nação. No interior ou na cidade, a mistura foi o motor a partir do qual se inventaram "unidades" para o Brasil e seus padrões de autenticidade.

Usando outros termos, é possível afirmar que a idéia de um "Brasil mestiço" tem uma história, anterior a Gilberto Freyre, inclusive; e que tanto a idéia quanto a sua história estão relacionadas também aos polêmicos debates 
sobre o caráter nacional brasileiro, ocorridos entre o final do século XIX e o início do século XX.

O objetivo deste artigo é recuperar a historicidade desse debate e proporcionar uma reflexão sobre um tipo de produção intelectual que investiu na construção de uma versão mestiça da identidade nacional brasileira, ainda na primeira república. Afinal, tanto a abolição quanto a república provocaram entre os intelectuais uma espécie de tomada de posição em relação à população afro-descendente, pois era preciso pensar na incorporação dos ex-escravos seus descendentes à vida nacional e à própria identidade da nação. ${ }^{1}$

A reflexão proposta, entretanto, envolve necessariamente o diálogo com uma importante tese sobre a primeira república, defendida por vários historiadores nos anos de 1980-1990. Essa tese afirma que o pensamento intelectual da chamada Belle Èpoque, especialmente na capital da república, voltava-se de modo praticamente total para valores externos e para a europeização dos costumes. Segundo esses estudos, desejava-se enterrar o "Brasil antigo e africano", empecilho para a realização de seu projeto civilizatório. ${ }^{2}$

No entanto, para explicar o interesse de vários intelectuais, na época, por manifestações culturais associadas aos negros e mestiços, alguns historiadores, de uma forma próxima à argumentação anterior, afirmaram a existência de uma voga de exotismo e regionalismo, que teria invadido a cidade do Rio de Janeiro e outras capitais do Brasil, a partir do início do século XX. ${ }^{3}$ Esse exotismo - também uma moda européia -, embora deva ser levado em conta, não é suficiente para a compreensão de tão complexas questões, pois ignora a sociabilidade intelectual brasileira e continua a pressupor a imitação, a cópia da Europa.

De fato, é impossível negar a fascinação dos intelectuais pelo chamado "modelo francês" - que incluía também a valorização de inventários folclorísticos. Mas, ao dar voz aos argumentos desses intelectuais, não se pode

\footnotetext{
${ }^{1}$ José Murilo de Carvalho, "Brasil: nações imaginadas", in: Pontos e bordados. Escritos de história e política, Ed. UFMG, Belo Horizonte, 1998, p. 233-268.

${ }^{2}$ Para algumas obras importantes nas quais os autores defenderam essa tese, ver: Nicolau Sevcenko, Literatura como missão: tensões sociais e criação cultural na Primeira República, São Paulo, Brasiliense, 1983; Jeffrey Needell, Belle Époque tropical, São Paulo, Cia das Letras, 1993; Monica Pimenta Velloso, Tradições populares na primeira década do século 20, Rio de Janeiro, FUNARTE, 1988; Martha Abreu Esteves, Meninas Perdidas, os Populares e o Cotidiano do Amor no Rio de Janeiro da Belle Èpoque, Rio de Janeiro, Paz e Terra, 1989.

${ }^{3}$ Sobre esse ponto de vista, ver Hermano Vianna, O mistério do samba, Jorge Zahar, 1995; Santuza Cambraia Naves, O Violão Azul, Modernismo e Música Popular, Rio de Janeiro, Fundação Getúlio Vargas, 1998; Nicolau Sevcenko, Literatura como missão..., op. cit.
} 
entendê-los somente a partir de explicações sobre o "gosto pelo exótico" ou sobre sua adesão a uma moda artístico-científica européia de interesse pelas coisas etnográficas. Até porque tiveram de pensar a partir de questões internas, como a seleção, dentro de um universo bem variado, do que seria brasileiro, as disputas em torno da centralização e da descentralização do poder, as teorias raciais, o passado escravista e o futuro da nação republicana. ${ }^{4}$

Mas, seja no caso das tradições populares encontradas nos recônditos do interior do país e sua correspondente mestiçagem, cujo fruto seria o mameluco, o caboclo ou o sertanejo, um tipo nacional de "alma mestiça", sem que sua cor fosse mencionada; seja no caso das expressões culturais urbanas e da afirmação de uma mestiçagem na qual a presença negra era mais forte, originando o mestiço "não-branco", o que se buscava era a unidade nacional. Com base na comparação entre o Almanaque e a Kosmos, embora a mistura das três raças tenha sido assumida positivamente como a maior originalidade nacional, podemos indicar que a mestiçagem no Brasil, do ponto de vista intelectual, não foi um fenômeno interpretado de forma homogênea. A variedade de manifestações culturais era grande, tão grande quanto as possibilidades de escolha sobre o que valorizar e condenar.

Assim, determinadas contribuições de negros e mestiços foram reconhecidas e divulgadas em periódicos inseridos em um circuito comercial, produtos culturais que precisavam ser vendidos e eram comprados por leitores que estavam dispostos, se não a concordar, ao menos a debater tais questões. Os próprios projetos editorais do Almanaque e da Kosmos, ainda que sob diferentes perspectivas, tinham em comum o empenho em transformar o conhecimento sobre o Brasil publicado em suas páginas em reconhecimento nacional. ${ }^{5}$

\section{Diálogos com a historiografia}

Autores como Renato Ortiz, Roberto Ventura, Lilia Schwarcz e Claudia Matos localizaram uma intensificação nos debates em torno da mestiçagem e do negro, a partir das últimas três décadas do século XIX, em meio à in-

\footnotetext{
${ }^{4}$ Essas reflexões foram desenvolvidas em conjunto com Martha Abreu em outro artigo. Ver, Martha Abreu; Carolina Vianna Dantas, "Música popular, folclore e nação no Brasil, 18901920", in: José Murilo de Carvalho (org.), Nação e Cidadania no Império. Novos horizontes, Rio de Janeiro, Civilização Brasileira, 2007, p. 123-151.

${ }^{5}$ Sobre a relação entre divulgação de conhecimentos nacionais e reconhecimento de códigos identitários nesse momento, ver Lucia Lippi de Oliveira, "Questão nacional na primeira república”, in: A década de 1920 e as origens do Brasil moderno, São Paulo, Editora da Unesp/ FAPESP, 1997, p. 186.
} 
trodução das teorias evolucionistas e científicas e à campanha pela abolição no Brasil. ${ }^{6}$

Segundo Lilia Schwarcz, essas teorias opunham-se ao Humanismo do século XVIII e deixavam de lado o princípio universal da igualdade, herdado da Revolução Francesa, “(...) que buscava naturalizar a desigualdade em sociedades só formalmente igualitárias”. Contraditórios, o Humanismo e as teorias raciais existiram num mesmo tempo, tendo sido até mesmo combinados. E foi nesse contexto que o argumento racial adquiriu outros significados, não limitados à definição biológica. O termo raça, historicamente construído, recebeu uma interpretação social e, dessa forma, não pode ser tomado como uma idéia fixa ou natural. ${ }^{7}$

Portanto, foi a partir da segunda metade do século XIX que tanto os monogenistas quanto os poligenistas assumiram a perspectiva evolucionista e ao conceito de raça foi dado um significado original. As teorias de Darwin - cujo enfoque se referia estritamente à natureza e ao ramo biológico - se tornaram referência obrigatória e forneceram uma nova orientação que foi aplicada à antropologia, à sociologia, à história, à economia etc. No plano político, por exemplo, o darwinismo foi tomado como base para projetos conservadores como o imperialismo europeu, ou seja, para o domínio sobre os supostamente "mais fracos e inadaptados". Assim, antigos debates tomaram novas proporções e rumos e os princípios monogenistas e poligenistas ${ }^{8}$ foram acionados em diferentes combinações com as, então, novas teorias raciais e evolucionistas.

Desde a entrada das teorias raciais no país, o Brasil passou a ser visto como espaço da mistura de raças, com todas as implicações que isso traria em termos de (im)possibilidade de progresso e de civilização. De acordo com as teorias raciais, a mestiçagem emergia nesse momento como uma incógnita,

\footnotetext{
${ }^{6}$ Ver Renato Ortiz, Cultura brasileira e identidade nacional, São Paulo, Brasiliense, 1986; Roberto Ventura, Estilo tropical. História cultural e polêmicas literárias no Brasil, São Paulo, Cia das letras, 1991; Lilia K. M. Schwarcz, O espetáculo das raças. Cientistas, instituições e questão racial no Brasil, São Paulo, Cia das letras, 1993; Claudia Matos, A poesia popular na república das letras: Sílvio Romero folclorista, Rio de Janeiro, FUNARTE/Ed. da UFRJ, 1994.

${ }^{7}$ Lilia K. M. Schwarcz, op. cit., p. 244.

${ }^{8}$ Segundo Lilia Schwarcz, os monogenistas teriam sido a corrente dominante até meados do século XIX, e baseava-se no Humanismo e nas escrituras bíblicas, defendendo que a humanidade era uma. Já os poligenistas teriam se firmado a partir da segunda metade do século XIX e acreditavam que existiam vários centros de criação que correspondiam às diferenças raciais, fortalecendo a concepção biológica dos comportamentos humanos, tidos como determinados pelas leis biológicas e naturais. Lilia K. M. Schwarcz, op. cit.
} 
uma ambigüidade que pairava sobre a idéia polêmica de paraíso racial. Ao mesmo tempo mácula e singularidade, a mescla de raças significava degeneração e ameaça ao futuro, mas também despertava curiosidade de estudiosos nacionais e estrangeiros. ${ }^{9}$ Certamente, essa não era uma afirmação que trazia conforto para os intelectuais brasileiros.

Mas, se no Brasil o argumento racial estava adequado ao estabelecimento e legitimação de diferenças sociais na pós-abolição, sua defesa podia implicar uma visão pessimista da mestiçagem e do próprio futuro do país. E foi exatamente nos meandros dessa tensão que saídas originais puderam ser elaboradas, acomodando modelos de matrizes diversas. De tal maneira, foi possível a adoção de determinadas assertivas, como a suposta diferença entre as raças e sua natural hierarquia, sem tocar no que isso traria de negativo; ou, ainda, uma leitura do darwinismo social que solucionou a idéia de que as raças humanas não permaneciam estacionadas, mas em constante evolução e "aperfeiçoamento", deixando de lado a noção de que a humanidade tinha uma origem comum e abrindo espaço para o a defesa do branqueamento. ${ }^{10}$

Silvio Romero foi um dos autores que se dedicaram profundamente a pensar nas relações entre raça, cultura e nação, entre o final do século XIX e o início do XX, influenciando seus pares e as gerações posteriores..$^{11} \mathrm{Com}$ posições por vezes ambíguas, partiu de uma afirmação clara: não adiantava debater se era bom ou ruim; o Brasil era um país composto por mestiços e isso era fato irrevogável. Reconheceu que tal fenômeno não era novo, mas que no Brasil, naquele momento, era mais intenso e flagrante. Era preciso refletir e propor soluções, ou seja, para alcançar o branqueamento era preciso conhecer as nossas heranças. ${ }^{12}$

De acordo com Roberto Ventura, as noções de mestiçagem e de branqueamento elaboradas por Romero configuraram uma dessas possibilidades de interpretação original das teorias raciais. O autor partiu da combinação entre a crença na existência inata de diferenças raciais e nas idéias evolucionistas, ou seja, na existência da concorrência pela vida e no predomínio do mais apto. Romero teria conjugado a mestiçagem - como fenômeno que diferenciava o Brasil das outras nações - ao branqueamento. E, a partir dessa diferenciação, o Brasil poderia superar a falta de originalidade da cultura nacional. Dessa forma,

\footnotetext{
${ }^{9}$ Lilia K M. Schwarcz, O Espetáculo das raças, op. cit., p. 12; p. 53.

${ }^{10}$ Idem, ibidem, p. 53-54.

${ }^{11}$ Claudia Matos, op. cit.

${ }^{12}$ Silvio Romero, "Brasil Social IV (o negro)", Renascença, n. 29, julho, 1906.
} 
o médico sergipano condenava o mestiço como racialmente inferior, ao mesmo tempo em que atribuía à mestiçagem o papel de única saída ou garantia, para a criação de uma cultura não-imitativa. A mestiçagem seria o único fator que conferiria originalidade ao Brasil, ainda que isso não significasse obrigatoriamente riqueza e vigor. ${ }^{13}$ Portanto, a reavaliação e a redefinição da mestiçagem conferiram a Silvio Romero uma posição que, a um só tempo, o distanciava e aproximava das teorias raciais. ${ }^{14}$ Para ele, pensar sobre "o mestiço" implicava necessariamente assumir e estudar o "(...) elemento africano, que por mais que queiramos esconder, predomina ainda em nossas populações... (...)”. ${ }^{15}$

Essas ambigüidades foram comuns na trajetória intelectual de Silvio Romero; atrelado que estava aos paradigmas do evolucionismo e do racismo científico, destacou as contribuições do negro, imputando a elas outras tantas reduções que acabavam por lhes retirar a relevância. A maior de todas as reduções cometidas pelo autor relaciona-se às suas considerações sobre a mestiçagem: “(...) a ação do negro é muito apreciável na formação do mestiço. Se não se conhece um só negro, genuinamente negro, livre da mescla, notável em nossa história, conhecem-se inúmeros mestiços, que figuram entre os nossos primeiros homens". ${ }^{16}$ A partir da mestiçagem, Silvio Romero resgatou o negro e ao mesmo tempo o subsumiu, uma vez que o branqueamento pressupunha o predomínio do elemento branco. ${ }^{17} \mathrm{O}$ mestiço, para Romero, seria uma espécie de "ganho evolutivo", pois teria ajudado o colonizador branco a se adaptar ao meio nos trópicos e incorporado índios e africanos à civilização.

Pensando nessas possíveis interpretações, ao avaliar a perspectiva do debate cultural dos intelectuais do Garnier e da Kosmos, parece que a penetração das teorias raciais não impediu outras saídas otimistas para se pensar a nacionalidade e o próprio futuro da nação - saídas que, embora estivessem dentro dos paradigmas raciais, valorizaram a mestiçagem e o mestiço como (produtores de) singularidades nacionais.

Desde o final do século XIX, a idéia de um "Brasil-cadinho" vinha sendo forjada e a categoria mestiço, para autores como Silvio Romero, Nina Rodrigues e Euclides da Cunha, fazia parte de uma linguagem capaz de expressar a realidade social desse período. E, dentro de certos limites, também

\footnotetext{
${ }^{13}$ Roberto Ventura, op. cit., p. 51.

${ }^{14}$ Claudia Matos, op. cit., p. 111.

${ }^{15}$ Silvio Romero, Estudos sobre a poesia popular, Petrópolis, Vozes, 1977, p. 49.

${ }^{16}$ Idem, História da literatura brasileira, Tomo 1, p. 111 apud Claudia Matos, op. cit., p. 118.

${ }^{17}$ Claudia Matos, op. cit.
} 
correspondeu a uma busca pela identidade nacional, o que fica evidente a partir da pesquisa em periódicos publicados na primeira década do século $\mathrm{XX}$, bem como a existência de outras mediações além das teorias raciais. Para Ortiz, independentemente das críticas (que supôs isoladas) cunhadas por Manoel Bomfim, o racismo científico foi a moeda corrente no debate político e cultural brasileiro entre o final do século XIX e início do XX, redefinido e adaptado às condições locais. ${ }^{18}$

A partir do paradigma racista, autores como o próprio Silvio Romero, Joaquim Nabuco, Afrânio Peixoto e João Baptista de Lacerda, por exemplo, enalteceram a mestiçagem como instrumento de assimilação racial dos considerados grupos inferiores, de forma que escapavam da armadilha determinista que condenaria o Brasil ao atraso e à barbárie. ${ }^{19}$

Mais próxima ou mais distante do branqueamento, a adesão à mestiçagem significou fundar os mitos da identidade nacional na fusão e na integração de raças e culturas. Entre a certeza da inferioridade do africano de Nina Rodrigues; a mestiçagem como originalidade tendendo ao branqueamento de Silvio Romero e de Gonzaga Duque; as investidas seletivamente consagradoras no mestiço de Lima Campos, as colocações ambivalentes de Olavo Bilac e a recusa da raça como fator determinante de Juliano Moreira ${ }^{20}$, oscilaram as posições sobre mestiçagem, negros e mestiços nos periódicos pesquisados. Havia, portanto, vários tons na abordagem da questão, assim como outras mediações e matrizes que, juntamente com as teorias raciais, faziam parte de um mesmo universo intelectual.

E ainda que a noção de intelectual não tivesse limites claros no início do século XX, relacioná-la à idéia de um "produtor de bens simbólicos" localizado na arena política, institucionalizada ou não, ajuda a reforçar o argumento de que esses intelectuais estavam comprometidos com projetos de intervenção naquela sociedade. No que diz respeito à atuação em campos de saber, a noção de intelectual com a qual estamos nomeando esses homens letrados possui contornos fluidos, até porque, salvo algumas raras exceções, escreviam muito na imprensa e sobre diversos assuntos. Estamos falando de

\footnotetext{
${ }_{18}$ Renato Ortiz, op. cit., p. 62.

${ }^{19}$ Idem, ibidem, p. 62-63.

${ }^{20}$ Nina Rodrigues, "As belas artes dos colonos pretos do Brasil - a escultura", Kosmos, n. 8, agosto, 1904; Gonzaga Duque, "O poeta negro", Kosmos, n. 2, fevereiro, 1909; Lima Campos, "A capoeira”, op. cit.; Lima Campos, "Cake-walk”, op. cit.; Fantasio/pseud. de Olavo Bilac, "A dança no Rio de Janeiro", op. cit.; Augusta P. Moreira, "Homens de cor no Brasil", Almanaque Brasileiro Garnier, 1910, p. 352-359.
} 
polígrafos, isto é, de um intelectual que deve “(...) ser pensado sempre como um doublé de teórico da cultura e de produtor de arte, inaugurando formas de expressão e refletindo sobre as funções e desdobramentos sociais que tais formas guardariam". ${ }^{21}$

Na pesquisa mais ampla ${ }^{22}$ da qual esse artigo é fruto, foi possível perceber que esses intelectuais compartilhavam alguns traços, como a abordagem de temas relacionados à identidade nacional, uma postura tutelar em relação à sociedade e a intensa atuação na imprensa. A maioria deles nasceu na região nordeste e morreu na cidade do Rio, evidenciando que a "república das letras" tinha o seu epicentro na capital federal. Além disso, a maior parte dos intelectuais pesquisados era de filhos de profissionais liberais, comerciantes, pequenos ou grandes proprietários em decadência, ou seja, não pertenciam ao que se pode chamar de "alta aristocracia brasileira", quer política quer econômica. Quase todos freqüentaram alguma instituição de estudos superiores, seja nas faculdades da Bahia, Recife, São Paulo ou Rio; originando ou não diplomas, as escolas superiores representaram espaços de contatos e sociabilidade fundamentais para esses homens. Notou-se um significativo envolvimento com a educação. A ocupação de cargos nos médios e baixos escalões da burocracia estatal é do mesmo modo uma constante, o que não deixa de ser uma forma de participação na política institucional, embora não partidária. Mais um ponto em comum entre esses intelectuais era o convívio em cafés, confeitarias e livrarias - locais que eram o ponto de encontro no qual se travaram relações de amizade, contatos sociais, intelectuais e profissionais. ${ }^{23}$

Foi possível localizar, também, tanto a partir da presença de alguns desses intelectuais nos movimentos de luta pela abolição e pela república (como Coelho Netto, Olavo Bilac, José Veríssimo, João Ribeiro, Rocha Pombo, Mário Mello, Graça Aranha, Gonzaga Duque, Lima Campos, Ernesto Senna e Xavier da Silveira Junior), quanto através das menções posteriores a esses acontecimentos (como nos casos de João do Rio, Joaquim Vianna, Curvelo de Mendonça e Gil), que tais processos tiveram um peso significativo em suas reflexões. Vale destacar ainda a presença de membros da Academia Brasileira de Letras dentre os autores estudados.

\footnotetext{
${ }^{21}$ Angela de Castro Gomes, Essa gente do Rio. Modernismo e nacionalismo, Rio de Janeiro, Editora FGV, 1999, p. 37-39; p. 13.

${ }^{22}$ Carolina Vianna Dantas, O Brasil café com leite: história, folclore, mestiçagem e identidade nacional em periódicos. Rio de Janeiro, 1903-1914, Tese de doutorado (Doutorado em História), Programa de Pós-graduação em História/UFF, 2007.

${ }^{23}$ Mônica Pimenta Velloso, Modernismo no Rio de Janeiro, Rio de Janeiro, FGV, 1996, p. 47.
} 
Tais informações ajudam a identificar melhor quem eram esses intelectuais e o próprio espaço que existiu nessa "república das letras" para uma diversidade de formulações sobre a mestiçagem e o preconceito de cor. Certamente não se restringiram somente às teorias raciais, à rejeição irrestrita do que estivesse relacionado aos negros e mestiços, ou mesmo, à simples idealização de um país futuramente branco. Acompanharemos a seguir algumas dessas formulações.

\section{A valorização do papel dos africanos e seus descendentes e o preconceito decor no Brasil}

A argumentação de Gonzaga Duque em uma crônica publicada na Kosmos sobre o seu admirado amigo Cruz e Souza nos traz pistas dessa variedade de abordagens sobre a mestiçagem e sobre a presença negra no Brasil. Segundo o autor, "o poeta negro" trazia consigo o "pesar da cor". "Intelectualmente superior, doía-lhe a diferença deprimente da sua raça, que nele, por compreensível supersensibilismo (...) atingia a forma duma desgraça." Descrevendo-o como portador de um forte recalque racial, Duque mencionou ter ouvido do amigo que o fato de ter nascido negro era acidental, mas raramente ele se referia a tal "acidente" com humor, como faziam "alguns homens intelectuais de sua raça”. Cruz e Souza se sentia perseguido e hostilizado pelo seu chefe na Repartição - um mulato do qual sempre se queixava: "É que eu lhe recordo a origem (...) dizia-me - tenho talvez a mesma cor da mãe... e ele, que quer ser moreno à força, esbarra-se comigo, vê-me como a afirmação tremenda do seu passado, sou o espectro recordativo da mucama que o despejou no mundo". ${ }^{24}$ O "talentoso negro" não se conformava com a repulsa manifestada por um "assimilado" em relação aos indivíduos de sua "raça ancestral", reagindo sempre com "amargor" e "acabrunhamento". 25

Mas, de acordo com Duque, essas tensões em torno da cor não deveriam ganhar a posteridade porque a mestiçagem, ao mesmo tempo em que eliminaria o "elemento negro" (de "tipo conservado", como Cruz e Souza), acabaria também com o próprio preconceito de cor. Para o futuro só interessaria o poeta Cruz e Souza e não a sua forma agressiva de lidar com o preconceito de cor. Logo, seu nome deveria se firmar e nunca se apagar do "grupo intelectual de

${ }^{24}$ Gonzaga Duque, "O poeta negro", Kosmos, n. 2, fevereiro, 1909.

${ }^{25}$ Uma dessas críticas carregadas de referências raciais foi feita a Cruz e Souza, na revista Kosmos, por José Veríssimo. Ver José Veríssimo, "Vida literária - uma poetisa e dois poetas", Kosmos, n. 1, janeiro, 1905. 
uma raça que tem dado, dentro do seu tipo conservado, homens de real valor mental e moral", como o pintor Manuel da Cunha, os Dias da Cruz, Luiz Gama, os Rebouças, Paula Brito e Rangel de São Paio. Aqui podemos observar uma aposta mais explícita no branqueamento. A "raça ancestral" foi valorizada no passado, no legado cultural deixado para o presente, mas a presença em carne e osso de negros "de tipo conservado" traria inconvenientes, em termos do preconceito de cor, que logo desapareceriam através da mestiçagem, para alívio do escritor.

Já para o cronista Gil a definição de um tipo homogêneo para a nação implicava o "abrandamento" da "raça negra" pela mestiçagem, ou seja, pela "assimilação de elementos estranhos". Embora projetasse um tipo nacional no qual a presença africana não fosse explícita na aparência, Gil defendeu, numa formulação intrincada, que não se deveriam apagar todos os traços capazes de conferir originalidade ao Brasil. Optou por um tipo nacional que deveria ter como “(...) traço iniludível, o leve dourado da face, a insurreição mal refreada dos cabelos, o olhar insinuante e elástico (...)" ${ }^{26}$

Além desses, há outros registros que nos permitem confirmar a existência, na primeira década do século XX, de concepções que matizaram o determinismo racial vigente e trouxeram à tona elaborações intelectuais que, mesmo construídas em diálogo direto com as teorias raciais, valorizaram, de alguma forma, negros, mestiços e a própria mestiçagem. Ao que indica a documentação, aquele era um universo intelectual caracterizado pela pluralidade de posições, autorizando-nos a considerar a mestiçagem como uma espécie de campo de conflitos e negociações. Nesse sentido, é que apresento ao leitor um pouco mais dos interessantíssimos registros de intelectuais sobre negros, mestiçagem e preconceito de cor.

A contestação do determinismo racial operada por Manoel Bomfim será o nosso ponto de partida. Dentro da linguagem biológica do seu tempo, este autor refutou a aplicação, segundo ele inapropriada, das teorias biológicas à sociedade humana. A fim de compreender o atraso em que se encontravam a América Latina e o Brasil, o autor investiu na análise dos problemas herdados do período colonial, chegando à conclusão de que o atraso tinha motivações históricas derivadas da exploração predatória operada por espanhóis e portugueses na América Latina - o que vinculou à idéia do parasitismo.

${ }^{26}$ Gil, Crônica, Kosmos, n. 5, maio, 1904. 
Portanto, teria sido a colonização ibérica predatória a origem dos problemas nacionais e não a pretensa inferioridade racial dos povos que viviam nesse território. Dessa forma, Bomfim rechaçou a visão corrente na Europa de que a América Latina era composta de países habitados por gentes preguiçosas, mestiços degenerados e bárbaros incapazes de organizar verdadeiras nacionalidades. ${ }^{27}$

Para ele, as teorias biológicas racistas eram um sofisma, isto é, uma justificativa “(...) mascarada de ciência barata e covardemente aplicada à exploração dos fracos pelos fortes". ${ }^{28}$ Ao apontar as incoerências das teses racistas de Agassiz sobre a pretensa inferioridade do mestiço no Brasil, demonstrou o quão anacrônico era o autor, pois defenderia premissas já refutadas pelos novos estudos europeus:

É horrível o que o naturalista da "imutabilidade das espécies" observou dos mulatos e mestiços brasileiros; (...) Não há razão para que nos impressionemos com os conceitos do sábio reacionário; ele andava por estes mundos com o propósito determinado de achar provas de que foi o Padre Eterno quem fez, bem separadamente, em momentos diferentes, cada uma das espécies existentes, e que elas são hoje o que eram quando saíram das mãos do obreiro lá dos céus (......$^{29}$

Em publicação de 1905, ao examinar a questão da mestiçagem, Bomfim refutou com argumentos históricos e sociológicos as qualidades negativas imputadas aos africanos e seus descendentes - como "submissão incondicional", "frouxidão de vontade", "docilidade servil", "afetividade passiva" -, afirmando que tais características, quando presentes, eram frutos das condições históricas e sociais a que foram submetidos, ou seja, da escravidão, da exploração e do abandono.

Para operar esse rompimento com as teorias raciais, Bomfim fez uso de outras referências teóricas, recorrendo a autores como Ribot, Waitz, Marlin De Moussy e Quatrefages. Na leitura de Bomfim, ao contrário do que diziam as teorias racistas, Ribot, por exemplo, acreditava que a mestiçagem poderia misturar qualidades morais e intelectuais e dar origem ao "aparecimento de aptidões novas". Com base nesses autores, argumentou que a mestiçagem teria desenvolvido no Brasil "qualidades apreciáveis", como a ausência de

\footnotetext{
${ }^{27}$ Manoel Bomfim, América Latina. Males de origem, Rio de Janeiro, Topbooks, 1993, p. 39. $1^{\text {a }}$ edição em 1905.

${ }^{28}$ Idem, ibidem, p. 243.

${ }^{29}$ Idem, ibidem, p. 263.
} 
preconceito de cor, possibilitando aos mestiços um pleno desenvolvimento de suas aptidões, como a superioridade artística em relação às raças mães. A quase totalidade dos pintores e músicos brasileiros seria de mestiços, havendo também muitos notáveis na medicina. Logo, os problemas pelos quais passavam os mestiços não diferiam em nada das populações européias que não tinham acesso adequado à educação:

Dêem-lhes interesses superiores, e dali nascerão sociedades estimáveis. Fortes e vigorosos como são, eles saberão aproveitar ultimamente as energias e resistências que possuem, e que os tornam efetivamente superiores aos colonos que se fazem recrutar nos refugos das civilizações corrompidas. ${ }^{30}$

Dando um tom nacionalista e antiimperialista ao seu anti-racismo, Bomfim investiu em argumentos históricos para refutar o arcabouço racista, afirmando que a solução para o atraso do Brasil estava na ampliação do ensino e da habitação adequada e na diversificação da economia para além da monocultura; o verdadeiro problema, a falta de "instrução popular", o que seria "curável, facilmente curável". ${ }^{31}$

Um incidente comentado por Olavo Bilac na Gazeta de Notícias, em 1907, também é revelador dos matizes com que a mestiçagem e o preconceito de cor foram concebidos na época. A ocasião deu ensejo a uma dura crítica do autor à ingratidão dos brasileiros que se envergonhavam da "raça mártir" - "a raça a quem mais devemos”. Ao contar da viagem do General Roca para São Paulo, mencionou um contratempo que teria acontecido em uma parada na cidade de Resende. Em meio a foguetes e bandas de música, um octagenário negro, veterano da guerra do Paraguai, ${ }^{32}$ teria gritado: "Viva o Imperador!", oferecendo ao general um cacho de bananas. De acordo com Bilac, diante da manifestação "burlesca e comprometedora", os brasileiros presentes ficaram muito constrangidos porque quando os argentinos queriam “(...) cobrir-nos de ridículo (...)" lançavam à face dos brasileiros

(...) justamente esses dois estigmas: os nossos pretos e as nossas bananas. $\mathrm{E}$ ali estava um preto oferecendo bananas ao general Roca!... Imaginais o pasmo da comitiva? Os que não coraram de vergonha, riram de malícia... Não sei até

\footnotetext{
${ }^{30}$ Idem, ibidem, p. 267.

${ }^{31}$ Idem, ibidem, p. 299-351.

32 Ver, nesse mesmo sentido, Dionísio Cerqueira, "O rosário do Cabo-de-ordens", Kosmos, n. 5, maio, 1908. Neste artigo o narrador discorre sobre a vida de um liberto, filho de pais alforriados, que teve uma atuação heróica na Guerra do Paraguai.
} 
como não se levantou ali algum punho colérico para fulminar com um soco patriótico imprudente, o homem que ousava, com sua presença bárbara, perturbar a harmonia da festa civilizada. ${ }^{33}$

Diferente dos "bonifrates" brasileiros da comitiva, o general Roca não teria rido nem se indignado: recebeu o "preto" com benevolência, saudou-o quando soube que era um veterano da guerra do Paraguai, aceitou as bananas e gratificou o "pobre ancião". A partir desse ponto, Bilac desfez a oposição entre a "presença bárbara" e a "harmonia da festa civilizada", propondo que os valores trazidos por ambas deveriam ser integrados.

Preocupado com a questão, Bilac indagou de que os brasileiros teriam vergonha ou achariam graça, pois ali estava uma pessoa que deveria ser respeitada não apenas pela sua idade, mas por representar a “(...) velhice na nossa terra, o nosso passado, a nossa tradição. Estava ali a raça mártir que nos desbravou a terra, que a regou com o seu sangue, que a defendeu, que a formou, que a enriqueceu!". A história daquele "preto" de carapinha seria a de muitos outros pretos que vieram para cá ou aqui haviam nascido cativos; que se fizeram homens "debaixo do azorrague e do opróbrio" e que conquistaram a liberdade em troca de uma nova escravidão, pois foram lutar no Paraguai "e lá se bateram sem saber porquê se batiam". Na volta, teriam sido abandonados à própria sorte pelo governo e pela sociedade, envelhecendo na "ignorância, na ociosidade e no abuso da aguardente (...) numa terra em que até hoje a organização do trabalho é um mito". Bilac considerava que aquele homem era um sobrevivente tanto da guerra quanto do egoísmo dos que não se importaram com ele após o seu retorno ao Brasil. Então por que a vergonha e o riso, justamente em um país que se orgulhava de ter assimilado a "raça negra"? Bradando contra o "desprezo" corrente contra os negros, defendeu que eles deveriam ser assumidos no passado e no presente:

Nós todos costumamos dizer, com uma basófia retumbante, que não desprezamos a raça negra, que a incorporamos dignamente em nossa civilização, que não a perseguimos, nem a exterminamos. Não a exterminamos pelas armas, é certo. Mas não é menos certo ainda que a tratamos sempre com desdém. Aqui, os brancos desprezam os pretos; os mulatos claros dizem que são brancos, e os

\footnotetext{
${ }_{33}$ Olavo Bilac, "Crônica”, Gazeta de Notícias, 24/03/1907, in: Antonio Dimas, Bilac, o jornalista. Crônicas, v. 1, São Paulo, Imprensa Oficial do Estado de SP/EDUSP/Ed. UNICAMP, 2006, p. 817-821. Ver, nesse mesmo sentido, Domingos Olimpio, "O Doutor Conceição", Kosmos, n. 5, maio, 1904. Nesse texto o autor relata o "preconceito de cor" sofrido pelo médico negro Pedro da Conceição.
} 
mulatos escuros dizem que não são descendentes de pretos, mas descendentes de tamoios e de tupiniquins. É ainda uma raça maldita! e, entretanto, o Brasil foi feito por ela...Oh, a nossa cruel tolice! a nossa estúpida presunção! Como se uma pátria pudesse anular o seu passado, alterar a sua tradição, destruir a sua história, toda facilmente como qualquer de nós deita ao lixo as botinas estragadas (...) Não, meus amigos e meus irmãos! (...) Não foi um incidente vergonhoso, nem um incidente ridículo. Nessas festas ao nosso amigo [general Roca], a homenagem do soldado ancião, do preto maluco, do cidadão humilde, foi a nota enternecedora. Aparecendo ali, inesperadamente, em pleno brilho do festival civilizado, o preto decrépito parecia estar dizendo: "Um momento amigo! eu também sou brasileiro, e dos mais dignos, apesar da minha cor, apesar da minha decrepitude, e apesar da minha baixa condição. ${ }^{34}$

Podemos perceber que Bilac dialogava com seus leitores assumindo que, embora se admitisse a integração dos negros, havia um forte preconceito de cor naquela sociedade, abrangendo, inclusive, as relações de negros e mestiços entre si. A insistência do autor na perspectiva da integração é incontestável, mormente ao defender que o Brasil deveria assumir sua herança africana com orgulho, mesmo que isso ainda fosse um motivo de constrangimento. Por outro lado, podemos atentar para o que estaria em jogo, para Bilac, nos debates em torno dos critérios de pertencimento à nação. A "raça negra", a decrepitude e a baixa condição pareciam não fazer parte do que os "boniferates" 35 do governo desejavam que fosse "o brasileiro".

Continuando nosso percurso pelos registros intelectuais em torno do preconceito de cor, encontramos mais uma vez Bilac preocupado em jogar por terra o que se dizia negativamente do Brasil em relação à sua forte presença negra e mestiça. Isso se deu na ocasião em que comentou o desdém com que uma atriz estrangeira se remeteu ao seu amigo José do Patrocínio, numa revista francesa chamada Je sais tout. A atriz era Jane Hading e se referia à vinda do ator Coquelin ao Rio: “(...) um deputado negro, em cena aberta, no Lírico, pregou ao peito desse ator a insígnia da Ordem da Rosa...”. Esta menção teria provocado a "nossa fúria patriótica". Bilac esclareceu que não se tratava de um deputado, mas de um vereador da Câmara Municipal: "o grande abolicionista José do Patrocínio". Impaciente, Bilac questionava o constrangimento causado pelo comentário no Brasil:

${ }^{34}$ Olavo Bilac, Crônica, Gazeta de Notícias, 24/03/1907, op. cit.

${ }^{35}$ Bonifrate significa: "boneco de engonços; autômato, títere./ Fig. Pessoa cuja aparência não corresponde à gravidade própria da sua idade, estado ou posição social”. Disponível em: www.kinghost.com.br/dicionario/bonifrate.html. Acesso em: jan. 2007. 
Ora, pois! Que coisa há, nesse fato, que nos possa envergonhar? Patrocínio, se não era negro, era quase negro. E desse quase negro, do seu talento, da sua formidável e esplendorosa ação social, da sua fúlgida glória de abolicionista, todo o Brasil se orgulha e se orgulhará sempre! (...) Vejam a grande desonra para um país: ter um deputado negro! Mas a França já teve uma porção de deputados negros, - e nem por isso o galo francês, o glorioso Chanteclair da Gália, perde o entorno da voz possante e a cor afogueada da crista! ${ }^{36}$

Se a França civilizada, modelo de progresso, tinha (ou já teria tido) deputados negros, o Brasil poderia assumir sua herança sem nenhuma implicação aos seus projetos modernizantes. Era o atestado na nossa compatibilidade (racial e cultural) com as grandes correntes universais. Para Bilac, Patrocínio era um homem negro que deveria ser fonte de orgulho nacional e não de desprezo ou vergonha.

Não resisto em apresentar mais um caso semelhante registrado por Bilac. O acontecimento se deu quando foi encenada na cidade do Rio a peça $O$ dote, de Arthur Azevedo, em italiano, por atores italianos. Na véspera do espetáculo, Bilac ouvira comentários de que a peça seria um fiasco, pois um ator italiano iria representar o “(...) velho preto João, que é um tipo exclusivamente, fundamentalmente, essencialmente brasileiro (...)”. Mas, segundo Bilac, “(...) o preto João interpretado pelo ator italiano foi um admirável preto”. Ao sair do teatro, o autor, teria encontrado novamente com o pessimista que previu erroneamente o fracasso da peça, preocupado que a companhia italiana de teatro fosse encená-la na Itália, justamente uma peça brasileira com um preto como personagem. Esse seria até um grande favor que os atores italianos fariam ao Brasil, divulgando nossas artes no exterior, mas para o "Sr. Nariz torcido" era motivo de vergonha ir mostrar na Europa que no Brasil havia pretos. Bilac criava mais uma vez a oportunidade de abordar o tema do desdém pelos negros, afirmando novamente seu importante papel na formação brasileira:

É esta uma das nossas manias: esconder o preto, disfarçar o preto, ter vergonha do preto, querer convencer a Europa da não existência do preto. Queremos tirar o preto das nossas fotografias, das nossas peças de teatro, dos nossos romances, da nossa história, da nossa raça e da nossa vida...Absurda e tola pretensão! Néscia e irritante mania! Nenhum povo altera, nem anula, nem precipita a sua história. O preto é inseparável, na constituição da nossa raça, dos outros elementos que têm contribuído e ainda hão de contribuir para

$\overline{36}$ Olavo Bilac, "O que se diz de nós", Correio Paulistano, 13/09/1907, in: Antonio Dimas, Bilac, o jornalista. Crônicas, v. 2, São Paulo, Imprensa Oficial do Estado de São Paulo/EDUSP/ Ed. UNICAMP, 2006, p. 78-79. 
formá-la. A mania não é apenas absurda e tola é também injusta, e reveladora de muita ingratidão. Foi o preto, afinal, que verdadeiramente criou esse país: lavrou a terra, regou-a com o suor, com o seu sangue e com as suas lágrimas; fecundou-a com o seu trabalho e com o seu sofrimento; preparou-a, com o seu obscuro sacrifício, para o radiante presente, de que ela já está gozando, e para o futuro, mais radiante ainda que a espera... Não há motivo para que reneguemos o preto, - nem no teatro, nem na vida real. O preto João de Arthur Azevedo não nos desmoralizará na Itália. Já temos para lá mandado muitos brancos de verdade, - muito piores do que esse pobre e generoso preto de ficção. ${ }^{37}$

Mais veemente que as anteriores, essa foi uma manifestação contra os paradigmas racistas em voga no momento, que apontavam a presença de negros e mestiços como estorvos ao progresso e à civilização. Note-se que em nenhum desses momentos o autor mencionou a necessidade de imigrantes nem o branqueamento e, ainda que tais questões pudessem estar implícitas em suas análises, não há como negar que Bilac estava travando um diálogo com tais paradigmas e combatendo-os.

Ciente de sua missão pedagógica, Olavo Bilac foi um dos que reagiam indignados ao que, segundo ele, seria a crescente americanização do Brasil, representada pela introdução do preconceito de cor aqui. O Brasil correria o risco de fazer aflorar os ódios de cor, caso se submetesse ao imperialismo dos Estados Unidos, país destacado como sendo racialmente segregacionista. ${ }^{38}$

De volta de uma viagem a São Paulo, o autor comentou sobre a proibição da entrada de "pretos e mulatos" - tomados por "incapazes e más figuras" - na guarda civil daquela cidade. O preconceito de cor, "o mais bárbaro e revoltante de todos os preconceitos", para Bilac deveria ser totalmente repudiado. Afinal, o que mais honrava e nobilitava a "civilização brasileira" era justamente

(...) a singela e admirável harmonia que ela estabeleceu entre as raças que contribuíram para a sua formação. A cor jamais impediu, no Brasil, que um homem galgasse as mais altas posições. Já no tempo do Império havia no Senado homens de cor. Vários mulatos, bem pouco disfarçados, foram ministros de Estado... Foi preciso que estabelecêssemos a República e que nos entregássemos de corpo de alma ao mais democrático de todos os regimes - para que alguém se lembrasse de excluir do seio de uma corporação os pretos e os seus descendentes! ${ }^{39}$

\footnotetext{
${ }^{37}$ Olavo Bilac, "Crônica”, Correio Paulistano, 23/06/1908, in: Antonio Dimas, Bilac, o jornalista. Crônicas, v. 2, op. cit., p. 198-199.

${ }^{38}$ Olavo Bilac, "Crônica”, Gazeta de Notícias, 21/01/1906, in: Antonio Dimas, Bilac, o jornalista. Crônicas, v. 1, op. cit., p. 773-774.
}

${ }^{39}$ Idem, ibidem, p. 774. 
Ao referir-se ao passado, Bilac trazia à tona exemplos dessa pretensa convivência racial harmônica, defendendo a mestiçagem como característica positiva e original da nacionalidade brasileira. A destruição da "grande obra confraternizadora das raças" empreendida no passado seria "um crime imperdoável", além de uma "revoltante ingratidão" com o "preto". Estaria ele se referindo a casos de preconceito de cor mencionados anteriormente como algo exclusivamente recente, que não aconteceria nos tempos do Império? Difícil saber. Como fundamento de seu argumento, Bilac expôs a realidade mestiça do Brasil, ao afirmar que nessa "perseguição imoral e vergonhosa exercida contra os homens de cor" não haveria somente ingratidão, mas também uma "filáucia cômica", pois nenhum brasileiro seria "completamente, absolutamente, legitimamente" branco, sem a mescla africana no sangue:

Lembrai-vos, amigos, que já o Marquês de Pombal foi um dia obrigado a lançar um decreto determinando "que todos dos fidalgos de Portugal, fosse qual fosse a sua ascendência, seriam, para todos os efeitos, considerados brancos...” É que lá, depois das conquistas na África, começou a nascer muito fidalgote de pele trigueira demais...E que diremos nós da nossa fidalguia agrícola, nascida entre o palácio e a senzala?40

Olavo Bilac defendia que o Brasil, em comparação com os Estados Unidos, era um país no qual existia mistura e tolerância racial, como provaria a nossa própria história - o que ele valorava positivamente. Mas, ao mesmo tempo, no início do século XX, bradou nos jornais contra o que seria para ele uma novidade no país: o preconceito de cor. Assim, a constatação histórica de que o Brasil era uma nação mestiça - originada de outra nação mestiça - legitimava a condição mestiça brasileira como singularidade. E isso não implicaria inferioridade racial nem impedimentos ao progresso e à civilização. Penso que o leitor já esteja percebendo que as teorias raciais fizeram parte daquele horizonte intelectual de diferentes formas, sobretudo quando tratadas no âmbito dos debates culturais.

O que dizer, então, do professor negro Hemetério dos Santos? ${ }^{241}$ Embora fosse alvo de troças racistas na imprensa, acreditava ser o Brasil uma obra de tolerância e amor, na qual os negros teriam um papel importantíssimo.

\footnotetext{
${ }^{40}$ Idem, ibidem, p. 774.

${ }^{41}$ Hemetério José dos Santos nasceu em Codó, no Maranhão, em 1858, e morreu na cidade do Rio, em 1939. Foi poeta, professor, gramático e filólogo. Foi professor e diretor do Pedagogium no Rio de Janeiro. Publicou "O livro dos meninos" (1881), "Pretidão do amor" (1905) - no qual defendeu os casamentos inter-raciais -, "Gramática portuguesa" (1913), "Frutos cativos, poesias" (1919).
} 
A famosa carta em que Hemetério criticava Machado de Assis logo após a sua morte foi publicada na Gazeta de Notícias, em 1908, e no Almanaque Garnier, em 1910. ${ }^{42} \mathrm{Na}$ carta, Hemetério acusava Machado de ter negligenciado o "problema do negro", fundamental na "vida de nação" brasileira. Diante disso, concluiu que o autor de Dom Casmurro partiu de "(...) idéias preconcebidas contra sua cor de procedência", enveredando-se por preconceitos "(...) vesgos e zarolhos".

Para o autor da carta, Machado teria apagado quaisquer vestígios significativos do negro em sua obra e, por isso, estaria muito aquém de homens como Rio Branco, Patrocínio, Arthur e Aluízio de Azevedo, Joaquim Nabuco, Silvio Romero, Rui Barbosa e "vários em legião", que não se furtaram à missão patriótica de referir-se ao negro na vida nacional. O preconceito contra sua própria origem teria marcado não só obras, mas a própria vida pessoal do bruxo do Cosme Velho, que teria renegado sua madrasta, uma "boa mulata velha"; a literatura pretensamente incolor de Machado, uma ofensa aos "seus irmãos de cor". Além disso, demonstraria que o autor não tinha tido ousadia suficiente para provar com fatos “(...) que a obra do português e do negro" não tinha "par no mundo, pela bondade e pela candura que ambos derramaram por toda a parte (...)". Dessa forma, para Hemetério, contrapor-se ao preconceito de cor implicava afirmar que o "problema do negro" no país não teria se desdobrado em antagonismos em função da própria contribuição dos negros. Nesse quesito, o Brasil seria tão original que deveria servir de exemplo para o mundo:

(...) a sociedade brasileira é sem modelo na história pelos exemplos de altas virtudes constantes, múltiplas e variadas desses três tipos que se irmanaram pelo sentimento, tornando-se um só espírito para a cultura do bem, desde os tempos de Vieira e Gregório. ${ }^{43}$

Era inaceitável para Hemetério que Machado de Assis se envergonhasse da cor da qual ele tanto se orgulhava. Defendendo essa mesma perspectiva, publicou um estudo no Almanaque Garnier contestando outro gramático, que garantia estar a palavra "preto" etimologicamente associada a algo desprezível e vil. Hemetério argumentou que tal afirmação não tinha fundamento nem na etimologia nem na linguagem popular. Na linguagem popular, por exemplo, o

${ }^{42}$ Hemetério dos Santos dirigiu uma carta aberta a Fábio Luz, publicada na Gazeta de Notícias, em 16/11/1908. Não interessa aqui avaliar se tais acusações têm fundamento ou não, mas analisar o que se pensava e como se lidava na época com o preconceito de cor e com a participação do negro na construção de uma identidade nacional.

${ }^{43}$ Hemetério dos Santos, "Machado de Assis", Almanaque Brasileiro Garnier, 1910, p. 369-374. 
vocábulo significaria "colorido mais forte que o negro, de uso mais geral para designar a raça simplesmente", o que o levou a crer que não existiam noções pejorativas associadas aos termos "preto" e "negro". 4

Mas o que diferencia o registro de Hemetério é o fato de ser negro e de ter sofrido publicamente com o "preconceito de cor". Se, por um lado, reconhecia a existência do preconceito de cor e posicionava-se contra ele, afirmava também o Brasil como uma nação construída com base no "amor" e na "tolerância". 45

Não menos interessante é a posição de Juliano Moreira, expressa em um texto escrito por sua esposa, a enfermeira alemã Augusta Moreira, e publicado no Almanaque Garnier, em 1910. ${ }^{46}$

De acordo com as idéias e experimentações de Juliano Moreira, explicava Augusta, era possível afirmar, com base científica, que negros e mestiços, independente da origem africana e/ou da mestiçagem, teriam as mesmas condições raciais que os brancos. Só o que poderia distingui-los era o meio em que viviam e a educação recebida. Uma prova disso era que, apesar de todos os "preconceitos de cor" existentes no Brasil, indivíduos descendentes de africanos tinham conseguido "atingir boas posições" nas mais variadas profissões e cargos, incluindo-se médicos, pedagogos e advogados respeitáveis. Existiriam "no Brasil pretos tão bons quanto brancos" e a única coisa que os distinguiria, ou que os deveria distinguir, eram os méritos, passíveis de serem alcançados por todos desde que se tivesse boa educação e se vivesse em boas condições sanitárias e mentais. A raça não distinguiria ninguém.

Se os "mulatos" no Brasil vinham, ao longo do tempo e em larga escala, distinguindo-se da "massa geral de seus compatriotas", como era o caso de Gonçalves Dias, Rebouças, Tobias Barreto e Patrocínio, como afirmar que a mestiçagem era um "empecilho aos surtos de inteligência"? Os maiores "defeitos" que os estudiosos da "questão negra" vinham atribuindo ao negro, como "imprevidência, imoralidade e improbidade", foram combatidos por Moreira com minuciosa argumentação e exemplos. Apostando na educação, o autor chegava à conclusão de que "(...) os defeitos dos pretos não são maiores que os dos brancos e (...) por intermédio da educação eles desaparecerão (...)”. ${ }^{47}$

\footnotetext{
${ }^{44}$ Idem. Etymologias. Preto. Almanaque Brasileiro Garnier, 1907, p. 237-239.

${ }^{45}$ Hemetério dos Santos, Machado de Assis, op. cit.

${ }^{46}$ Augusta P. Moreira, op. cit.

${ }^{47}$ Augusta P. Moreira, op. cit.
} 
Antes de ter seu artigo publicado no Garnier, entretanto, as questões relativas ao determinismo racial e ao preconceito de cor já mobilizavam o autor. Em 1896, depois de ser aprovado no concurso para professor da Faculdade de Medicina da Bahia, em seu discurso de posse, dirigiu suas palavras aos que tinham receio de que "(...) a pigmentação" fosse uma "nuvem capaz de marear o rilho" daquela Faculdade. Marcou sua posição, afirmando que nem a cor nem a raça deveriam importar, mas sim os méritos individuais. O que enegrecia a "pasta humana" eram o servilismo e a ignorância, não o negro:

Subir sem outro bordão que não seja a abnegação ao trabalho, eis o que há de mais escabroso. (...) Ver-se-á, então que só o vício, a subserviência e a ignorância são que tisnam a pasta humana quando a ela se misturam (...). A incúria e o desmazelo que petrificam (...) dão àquela massa humana aquele outro negror (...). ${ }^{48}$

O concurso prestado por Moreira para entrar para a Faculdade de Medicina foi um processo difícil. A banca era composta por homens conhecidos por seu passado escravocrata. Na manhã de maio de 1896, ao entrarem no prédio da Faculdade, os estudantes puderam conferir que Juliano Moreira havia sido aprovado com nota máxima. Aos 23 anos, o filho de uma doméstica com um funcionário da prefeitura tornou-se professor da Faculdade de Medicina da Bahia. ${ }^{49}$

Em diálogo com seus pares, Juliano Moreira defendia o papel da profilaxia, ou seja, a importância da educação e da higiene mental. Imbuído da perspectiva de "moralização das massas", analisou o problema dos negros africanos viciados em álcool, chegando à conclusão de que os elementos degenerativos não se relacionavam à raça, pois

(...) o álcool infiltrava-se nos neurônios os elementos degenerativos que, reforçados através dos tempos dão razão de ser a muita tara atual, atribuída à raça e à mestiçagem por todos aqueles que não se querem dar ao trabalho de aprofundar as origens dos fatos (...) a má natureza dos elementos formadores de nossa nacionalidade deve-se à degenerescência física, moral e social que injustamente tem sido atribuída ao único fato da mestiçagem. ${ }^{50}$

\footnotetext{
${ }^{48}$ A. PASSOS, Juliano Moreira (vida e obra), Rio de Janeiro, Livraria São José, 1975, p. 17-18. Ver também Anamaria Galdini Oda; Paulo Dalgalarrondo, "Juliano Moreira: um psiquiatra negro frente ao racismo científico”, Rev. Bras. Psiquiatria, dez. 2000, v. 22, n. 4, p.178-179.

${ }^{49}$ Anamaria Galdini Oda, "Teoria da degenerescência na fundação da psiquiatria brasileira: contraposição entre Raimundo Nina Rodrigues e Juliano Moreira”, Psychiatry On-line Braะil, n. 6, dez., 2001. Disponível em: www.polbr.med.br/arquivo/wal1201.htm. Acesso em: mar. 2006. ${ }^{50}$ Juliano Moreira apud Vera Portocarrero, Arquivos da loucura. Juliano Moreira e a descontinuidade da psiquiatria. Rio de Janeiro, Editora FIOCRUZ, 2002, p. 55-56.
} 
Partindo desses pressupostos, polemizou a respeito com seu conterrâneo Nina Rodrigues, baseando-se em casos empíricos, o que nos dá a medida das hesitações nesse momento em relação à questão racial. Moreira descreveu com a história de um paciente (chamado de A.P.D.), sua infância, os estudos até o segundo ano de direito, o seu retorno à casa dos pais, a doença e a morte. A.P.D. era um “(...) pequeno proprietário, falecido aos 55 anos de idade, mestiço, filho de italiano e de uma preta. Antecedentes hereditários - Pai bêbado habitual, mãe nada apresentava de anormal". ${ }^{51}$ Descontente com a interrupção de seus estudos, A.P.D. passou a preocupar-se demasiadamente com a questão dos limites de suas terras com as de um vizinho. Uma "paranóia querelante" levou o paciente a intermináveis processos judiciais durante 32 anos. $\mathrm{O}$ próprio Juliano Moreira verificou pessoalmente o caráter paranóico de APD. Entretanto, ao contrário do seu colega Nina Rodrigues, Moreira desassociava qualquer hipótese dessa "demência" estar ligada à mestiçagem:

(...) Tendo mostrado este doente ao Prof. Nina Rodrigues, achou ele no caso mais uma prova de que a mestiçagem é um fator degenerativo. Ora, tendo eu sempre me oposto a esta maneira superficial de ver o problema, aproveitei uma longa estada na Europa para examinar os parentes de A.P.D. que tinham ficado na Europa livres da mestiçagem. (...) Apurei o seguinte: o velho pai de nosso doente tivera dois irmãos e uma irmã. Dos primeiros, um também partiu para a América desertando das fileiras do exército. Dele não se sabe notícias. O outro, imbecil, ébrio habitual, turbulento, muito supersticioso, esteve preso duas vezes por ter ofendido fisicamente duas velhas (...) casou-se e teve dois filhos, ambos imbecis. A irmã epiléptica teve três filhos: um também epiléptico, um imbecil e o terceiro homicida, supõe-se que também epiléptico (...). Vê-se que o ramo europeu da família, livre da mestiçagem, em nada foi superior ao ramo mestiço brasileiro. (...) Intelectualmente mesmo A.P.D. apesar de paranóico era evidentemente superior aos seus primos italianos. Não afirmarei que o relativo lucro proveio do cruzamento, mas sim da circunstância de ser a mãe dele uma mulher sã, não tendo ele herdado sua eiva senão de seu pai, bêbado habitual, nada escrupuloso em negócios e com evidente tendência demandista. ${ }^{52}$

Segundo sua esposa, Juliano Moreira teria deixado claro que os estudos que concluíram pela inferioridade do mestiço "estudaram a questão muito unilateralmente", pois eram influenciados por uma "leitura apressada e errônea" dos trabalhos de Gobineau. ${ }^{53}$

\footnotetext{
${ }^{51}$ Juliano Moreira, Querelantes e Pseudo-querelantes. Arquivos Brasileiros de Psiquiatria, Neurologia e Medicina Legal, v. 4, p. 426-434, 1908.

${ }^{52}$ Idem, ibidem, p.431-432.

${ }^{53}$ Idem, ibidem.
} 
De uma maneira próxima ao argumento defendido aqui, mas investigando a construção de uma "História do Brasil", Ângela Castro Gomes sugeriu que "ao lado do amplo compartilhamento das teorias européias racistas que existia na virada do século $\mathrm{XX}$, crescem as divergências quanto à avaliação dos efeitos da miscigenação existente no Brasil, francamente constatada, mas nem sempre mais tão condenada". Logo, a crença no fundamento científico dessas teorias continuava latente, daí a própria difusão da ideologia do branqueamento. Mas, começava-se a avaliar de forma mais sistemática a presença ativa de índios e negros na história e cultura, que estavam sendo forjadas naquele momento como nacionais. ${ }^{54}$

Diante desses registros, podemos deixar de encarar intelectuais como Manoel Bomfim e Alberto Torres como isolados ou dissidentes, mas como participantes de um debate marcado por ambigüidades, é certo, e também por uma pluralidade de concepções. Por isso mesmo, operaram sensíveis deslocamentos no debate racial e cultural sobre a identidade nacional no período. Ainda que dentro do paradigma racial e em diálogo com ele, relativizaram o "peso negativo" da mestiçagem e do mestiço na formação nacional, valorizando a fusão como nosso mito de origem. ${ }^{55}$

Não se trata de minimizar o peso das teorias raciais, nem seus desdobramentos em termos das políticas voltadas para o branqueamento e para a repressão e o controle aos afrodescendentes na primeira década do século $\mathrm{XX}$; nem tampouco exaltar a eugenia e seus adeptos. Trata-se de trazer à tona outras mediações, fundamentais para se compreender a pluralidade das avaliações acerca do papel dos afrodescendentes na formação nacional. Paralelamente às teorias raciais que previam a inferioridade dos afrodescendentes e a degeneração dos mestiços às quais intelectuais, políticos, cientistas, médicos e juristas aderiram naquele período, é possível identificar investimentos de alguns intelectuais na descoberta e na difusão de manifestações culturais marcadamente mestiças. Como homens dentro do seu tempo, no entanto, esses intelectuais não escaparam das máximas racistas, mas também não desejaram banir negros e mestiços do cenário nacional, nem desprezaram suas contribuições ao que estavam definindo como elementos originais da "cultura

\footnotetext{
${ }^{54}$ Ângela de Castro Gomes. Gilberto Freyre: alguns comentários sobre o contexto historiográfico de produção da Casa grande e senzala. Remate de Males - Revista do Dept ${ }^{\circ}$ de Teoria Literária/UNICAMP, Campinas, 2000, p. 50.

${ }^{55}$ Ver Renato Ortiz, op. cit.; Eliana Dutra, The fusion of races as locus of memory, Diogenes, Oxford, n. 191, v. 48, 2000.
} 
brasileira", capazes de selar uma unidade nacional e harmoniosa para o Brasil. Também debateram sobre relações e conflitos raciais; alguns até denunciaram o preconceito de cor, firmando publicamente a posição de que não se devia apagar o negro, da nossa história, da nossa cultura e das nossas fotografias. Mas é evidente que as diferentes versões sobre o Brasil que tocaram no tema da mestiçagem trazem por certo noções hierarquizantes. Não podemos esquecer o silêncio desses intelectuais em torno da ampliação dos direitos políticos e trabalhistas, da questão da terra e etc.

\section{Uma chave de leitura para o Brasil}

A partir da abordagem da mestiçagem e do preconceito de cor no Brasil, alguns intelectuais de peso abriram possibilidades de conciliar as contradições de uma sociedade multirracial e hierarquizada.

Refletindo sobre o contexto de produção e recepção de Casa grande e senzala, a partir de um recuo às primeiras décadas do século XX, Ângela de Castro Gomes evidenciou os esforços dos intelectuais em conferir novos contornos aos debates em torno do papel do índio e do negro na história e na cultura do país. A autora, então, identificou um "clima favorável" ao acolhimento da obra, seja em relação ao uso de fontes históricas, à forma da narrativa ou à apreciação do negro/mestiço como presenças ativas na história e na cultura do país. Portanto, quando Casa grande e senæala foi lançada, em 1933, algumas das "inovações” trazidas por Gilberto Freyre já vinham sendo debatidas e outras valorizadas desde o início do século. ${ }^{56}$

Não se pretende postular um novo marco zero para o investimento na associação entre nação e mestiçagem no Brasil, nem afirmar que determinados intelectuais da primeira década do século XX estavam defendendo a mesma coisa que Gilberto Freyre defenderia a partir de Casa grande e senzala. Diferente do sociólogo pernambucano, estavam em busca da "substância" que faltava para que o Brasil fosse uma verdadeira nação (com atributos culturais e históricos singulares) e tivesse um povo de fato (isto é, uma população dotada de sentimento de pertencimento e irmanação).

Se, por um lado, as elaborações intelectuais apresentadas aqui constituíram o "clima favorável" para a ótima recepção de Casa Grande e Senzala, por outro lado, também fazem parte da história de uma forma duradoura de se pensar o Brasil.

\footnotetext{
${ }^{56}$ Ângela de Castro Gomes, Gilberto Freyre: alguns comentários...,op. cit., p. 50 e 56.
} 